\title{
Management of survival guilt by a Chinese widower through the use of continuing bonds
}

\author{
IVAN M. H. WOO ${ }^{1}$ \& CECILIA L. W. $\mathrm{CHAN}^{2,3}$ \\ ${ }^{1}$ Lien Centre for Palliative Care, Duke-NUS Graduate Medical School, Singapore, ${ }^{2}$ Department \\ of Social Work and Social Administration, The University of Hong Kong, Hong Kong, and \\ ${ }^{3}$ Centre on Behavioral Health, The University of Hong Kong, Hong Kong
}

\begin{abstract}
Death of a live organ donor as a result of organ transplantation is rare. However, such a death can be a devastating experience for the organ recipients, especially so if the donors are close relatives. Donor recipients commonly experienced survival guilt and this guilt may lead to complicated grief. Given the low prevalence of such deaths caused by organ transplantation, little is known about its impact on the survivor recipients. This lack of awareness may lead to disenfranchisement of grief in individuals who lose their close relatives.

Based on the conventionally neglected perspective of one Chinese widower whose spouse died after giving him a portion of her liver, this article documents how he managed his survival guilt through continuing bonds with his deceased spouse. Effects of continuing bonds are discussed and the article concludes with recommendations.

Continuing bonds highlighted in this article are defined as the integration of the deceased's identity into the life of bereaved individuals. In this study, it was observed that this integration may be therapeutic in elevating survival guilt experienced by Chinese individuals who have lost their close relatives after receiving the close relatives' organ.
\end{abstract}

KEYwORDS: survivor guilt; Chinese widower; organ transplantation; organ recipients; continuing bonds

\section{Introduction}

The shortage of organ donors is a concern for the international community. In the United States, it was estimated that there were 90,000 people on organ waiting lists at the end of 2005 and the overall percentage of people on the waiting list for organ transplantation with inactive status had increased from $14 \%$ in 1996 to $29 \%$ in 2005 (Port, Merion, Finley, Goodrich, \& Wolfe, 2007). It was also observed that a minimum of $20 \%$ of individuals on the waiting list for organ transplantation die every year (Cantarovich, 2002). In Hong Kong, organ shortage was also identified as a concern and it is believed that better professional awareness and

Correspondence: Ivan M. H. Woo, Lien Centre for Palliative Care, Duke-NUS Graduate

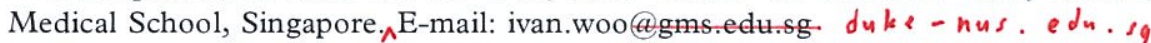

11 Hespital Drive Lerel 4 , Singape.e 169610

ISSN $1357-6275$ (print) ISSN 1469-9885 (online) (c) 2010 Taylor \& Francis

DOI: $10.1080 / 13576270903537633$ 
public education will alleviate the shortage, but not in the near future (Chui, 2002). However, it was found that people are a lot more willing to donate their organs as a gift of love if the recipients are the donor's relatives (Shanteau \& Skowronski, 1990).

\section{Survival guilt}

Making the decision to donate their organs to their relatives, donors take a risk that may result in either postoperative complications (Miyagi et al., 2005) or, in some cases, death (Vastag, 2003). Death of the donor may create survival guilt defined as, 'a universal experience for people to feel terrible when they survive an experience in which someone they love has died' (Blacher, 2000). Survivor guilt is a term that was first introduced by William G. Niederland when he described the survivor syndrome based on his clinical observations of close to 2000 concentration camp survivors. In describing survivor guilt, Niederland (1981) noted that individuals experiencing survivor guilt have a tendency to (1) selfblame, (2) experience a lifelong burden of pain and shame, and (3) have a desire to join the deceased person in death.

About a decade after Niederland introduced the term survivor guilt, clinical psychologist Therese A. Rando provided an excellent overview and additional insights on guilt (Rando, 1993). According to Rando (1993), 'guilt is the feeling of culpability deriving from perceived offences or a sense of inadequacy' (Rando, 1993, p. 478). It is a feeling that can be healthy if it exists in a certain amount because it helps promote appropriate behaviour. She has also highlighted that guilt can have two latent functions: (1) 'to defend against helplessness' and (2) to serve as self-punishment and a tool for retribution' (Rando, 1993, p. 478).

Since the 'introduction' of survivor guilt about two and a half decades ago, numerous studies have been undertaken on the phenomenon and it was found that survivor guilt is present in bereaved individuals, especially bereaved children and bereaved individuals who have ${ }_{\wedge}$ people to suicide or disasters (DeSpelder \& Strickland, 2005).

lost

Bereaved individuals stricken by the loss of people close to them after receiving an organ from them are another group of people at high risk of survival guilt. Often, such death of the donor is sudden and it can be difficult for the survivor (DeSpelder \& Strickland, 2005). To assist individuals in alleviating survival guilt that compromises their physical and mental health, Rando (1993) has proposed handling the guilt as a defence or resistance that must be worked through slowly. She advised professionals working with individuals experiencing survival guilt not to rescue their clients, but to work through the individuals' reasons for holding on to the guilt. For individuals who cannot alleviate their guilt, she proposed helping them to live with the guilt without allowing it to act as a tool for self-punishment (Rando, 1993). Thus, it appears that survival guilt may be alleviated or converted into positive energy through giving it new meaning.

In a rare case report, it was documented that individual therapy, trauma psychotherapy group and antidepressants were able to alleviate feelings of anxiety 
and hypervigilance but did not relieve the experience of survivor guilt in a survivor of the Vietnam war (Khouzam \& Kissmeyer, 1997). As a result of survivor guilt, the survivor relapsed into alcohol abuse until he joined an Alcoholics Anonymous group. After joining the Alcoholics Anonymous group, the survivor reported that he was no longer abusing alcohol and his survivor guilt had vanished, and he attributed this change to the spiritual awakening he had experienced while he was in the group. Towards the end of the report, it was highlighted that the absence of alcohol abuse and survival guilt had lasted six months after the survivor's spiritual experience. Thus, it appears that an intervention that helps one find new meaning in their experience may be more effective than conventional treatment in helping individuals alleviate their survivor guilt.

\section{Continuing bonds}

Engagement in continuing bonds would be one possible way that an individual may find new meaning from an attachment that creates self-punishing guilt. A discussion on continuing bonds would be incomplete without mention of the contribution made by John Bowlby in enhancing understanding of continuing bonds. A seminal figure in the development of attachment theory, Bowlby, contributed much to the earliest understanding of continuing bonds. Though he did not use the term explicitly, and his focus was primarily on the attachment between parent and child, his writings Loss: Sadness and Depression (1998) have given scholars valuable insights into continuing bonds. He states that,

The goal of attachment behavior is to maintain an affectionate bond, any situation that seems to be endangering the bond elicits action designed to preserve it; and the greater the danger of loss appears to be the more intense and varied are the actions elicited to prevent it (Bowlby, 1998, p. 42).

He also argues that this is not only the case for children but the case for adults and bereaved individuals too.

A more recent book on continuing bonds by Klass, Silverman, and Nickman (1996) promotes the central message that continuing bonds with the deceased are normal among bereaved individuals. In this article, $\stackrel{\text { we }}{\Psi}$ suggest that continuing bonds are not only normal, they have a key role in helping Chinese people to adjust healthily to conjugal loss. A description is given on how a Chinese widower, whose wife died from postoperative complications after she donated part of her liver to him, manages through continuing bonds with his wife to manage his survivor guilt and experience growth as a result of the healing process.

The data documented in this article are taken from a larger study exploring the experience of Chinese widowers after conjugal loss. The Chinese widower highlighted in this study was asked retrospectively to share his relationship with his deceased spouse before and during her illness and after death. Before the start of the interview, the purpose of the study was explained to the widower and his consent for participation obtained. The Human Research Ethics Committee for 
Non-Clinical Faculties in the University of Hong Kong granted approval for the study.

\section{Max's story}

Max (not his real name) was diagnosed with liver disease in 2004 and needed a liver transplant. When his wife, Jane (not her real name), knew about Max's medical condition, she decided to donate two-thirds of her liver to him. After Jane donated her liver to Max, she was discharged home when her condition stabilised, while Max continued to stay in the hospital for further observation. However, Jane developed complications on the day the doctor declared Max fit for discharge and was admitted into the same hospital as Max. Max managed to meet Jane when she was admitted and spoke to her for about two hours before returning to his bed.

However, on his second visit, he noticed that Jane's condition had taken a turn for the worse. Jane had vomited blood and had to have a feeding tube inserted into her stomach. This sight caused much pain to Max and he decided to stay with Jane at her bedside until their children arrived in the hospital to relieve Max of his vigil.

The next day, when dawn broke, Max received news that Jane has been admitted into the Intensive Care Unit (ICU) and he rushed to the ICU to meet Jane. When Max arrived in the ICU, he learned that Jane was in a critical condition; he knelt down on the corridor of the ICU and pleaded with God to forgive him and take his life if Jane could be saved. When he knew that Jane had died, he wanted to kill himself but was stopped by his children and the medical staff. Shortly after, he fainted.

Max had a lot of difficulty accepting Jane's death and started experiencing survivor guilt. He said he felt responsible for Jane's death. But for his liver disease, Jane would not have donated her liver to him and would not have developed postoperative complications and died. In the day time, he would curse and swear at God. However, the emotional pain became so acute at night that he started asking God to forgive him. When day broke, he would curse and swear at God again. This cycle went on for several months until one day marked a turning point. As Max was walking home he happened to pass by the garden in which he used to walk with Jane. He sat down in a pavilion in the garden and recalled the events leading to Jane's death. All of a sudden, he wanted to accept Jane's death and be realistic. For the first time, he felt that God was asking him to explain why he blamed Him and reminded him that Jane had become a Christian before she died and that she was alive in heaven. In retrospect, Max believed that God has been trying to reach out to him but he was too absorbed in his grief to listen to God. The time spent in the pavilion was the first time that Max allowed himself to hear God.

This spiritual awakening was so powerful that Max's life was transformed overnight. After getting the revelation that Jane was alive spiritually, Max decided to live a life of value and cherish the gift, the liver, which Jane had given him. $\mathrm{He}$ decided that he would become Jane's living legacy.

Max toldescri me that Jane was a very kind-hearted person whd would donate money to Oxfam when she was alive. She also did a lot of charity work and was a 
hardworking homemaker. Thus, Max changed Jane's name in the Oxfam account to his own and he started engaging actively in volunteer work in his church. He did everything that Jane would have enjoyed doing if she was still alive. During the interview, he told me that he was wearing Jane's shoes and he enjoyed wearing them because it reminded him of how hardworking Jane was; a trait that Max admired in Jane. Besides being Jane's living legacy, Max also talked to her. He toldme that he shared biblical songs with her and would communicate his thoughts and feelings to Jane through a diary. Whenever Max felt down, he would place his hands near his liver and a feeling of peace would descend upon him instantaneously. Max disclosed that he felt Jane's presence whenever he placed his hands near his liver and that presence provided him with much support.

At the time of the first interview, Jane had been dead for two years and Max had been Jane's living legacy for more than a year. One year after the first interview, a letter that Max wrote to his wife was published and awarded the top prize in a writing competition. In retrospect, Max felt that there was no other way he could live his life except to live the life that Jane would have lived if she was still alive.

\section{Cultural and psycho-social mechanisms in Hong Kong}

Hong Kong is widely known as a British colony that was returned to China in the year 1997. With colonisation and the subsequent return to China, a country that is transiting rapidly to modernity, a diverse culture has evolved in Hong Kong. This inevitably influences the cultural and psycho-social mechanisms of families in Hong Kong. In a rare article published about a decade ago, it was highlighted that Hong Kong families were at the crossroads of modernism and traditionalism (Chan \& Lee, 1995).

Today, it is observed that many families in Hong Kong are still at the crossroads of modernism and traditionalism. For example, in the case highlighted above, it can be observed that while Max has embraced Christianity, a religion widely embraced in the non-Chinese world, part of him still holds on to the view that he has a joint identity with his late spouse, a collectivistic identity commonly found in the Chinese world. According to Chan and Lee (1995), the term utilitarianistic familism coined by Lau (1981) would be a concept that would best explain the ability of families in Hong Kong to integrate values from the non-Chinese with those of the Chinese world.

Utilitarianistic familism is 'defined as the normative and behavioral tendency of an individual Chinese to place his familial interests above the interests of society and of its constituent individuals and groups in such a fashion that the furtherance of his familial interests is the primary consideration' (Lau, 1981, p. 978). In outlining the characteristics for utilitarianistic familism, Lau asserts that the phenomenon is characterised by 'primacy of familial interests, perception of the social-political context as the arena for the pursuit of familial interests, utilitarianistic considerations in the structuring of intrafamilial relationships, the nonsignificance of the social status of the familial group, utilitarianistic recruitment of familial members and the resultant vagueness of the boundary of 
the familial groups, and the dilution of authority relationships between familial members' (Lau, 1981, p. 977). Thus, it appears that Chinese people may weigh up the benefits that their familial group would stand to gain when placed in stressful situations which demand a decision.

In the above case, contrary to the perception of Chinese that many individuals hold, Max's wife decided to donate part of her liver to Max not because there was an expectation for her to give him her organ. Rather Max's survival was important for the furtherance of familial interests and that is what motivated her to donate her organ to Max.

\section{Continuing bonds in Hong Kong}

From Max's distress, agony, and guilt after Jane's death highlighted above, one can see that an organ recipient's grief can be extremely intense if the donor, a close relative, dies after the organ donation. However, there is hope for the alleviation of the emotional burden carried by the organ recipients. The promotion of continuing bond, 'a presence and connection with the deceased' (Silverman \& Klass, 1996), seems to help transplant survivors manage their survivor guilt caused by the death of their close relative who is the donor. Scholars working in the area of organ transplantation have found that organ recipients do report identification with the donors (Blacher, 2000; Sanner, 2003). However, there is no known report on the impact of the identification on the recipients.

In this article, one can see that the identification may have therapeutic value. In a recent publication, Chan et al. (2005) reported that continuing bonds with the deceased is a common phenomenon among Chinese bereaved individuals. These types of bonds can be separated into two main categories: continuing bonds initiated by the bereaved and continuing bonds initiated by the deceased. The former include conversations with the deceased's photo, visits to the graveyard, doing things that were done with the deceased when he or she was alive, finishing the deceased's unfinished business, giving regular offerings to the deceased, laying ashes of the deceased, and communication with the deceased through a spiritual medium. Continuing bonds initiated by the deceased include feeling, hearing, or seeing the deceased after their death, meeting the deceased in dreams, experiencing a visit by the deceased seven days after the deceased's death, and witnessing the deceased's return in the form of an insect (Chan et al., 2005).

The continuing bonds advocated for organ recipients stricken with guilt by the death of the organ donor who happened to be a close relative would be classified by Chan and her colleagues as continuing bonds initiated by the bereaved. However, in their paper, there was no mention that the integration of the deceased's identity could be a form of continuing bonds. This is surprising given that Klass (2006), in a recent attempt to revisit the concept of continuing bonds (published in 1996), stated that 'reconstructed social identity is what we have been calling a continuing bond in bereavement studies, but with the focus on the social nature of bonds with the dead rather than on individual grief responses' (Klass, 2006 , p. 850). Here, Klass appears to suggest that continuing bonds should be 
seen as a reconstructed social identity instead of responses triggered by grief. The categories under continuing bonds initiated by the bereaved highlighted by Chan and her colleagues appear to focus on responses triggered by grief. As a result of their focus, Chan and her colleagues during their data analysis may have missed out the integration of the deceased's identity as a possible category of continuing bonds.

\section{Value of continuing bonds in adaptation to bereavement}

Having advocated continuing bonds as a possible means to alleviate survivor guilt among Chinese people triggered by the death of an organ donor who happens to be a close relative, it is worthwhile noting that continuing bond may not be suitable for all individuals. For example, US psychologists Lalande and Bonanno have found that higher levels of continuing bonds four months after conjugal loss are associated with better adjustment at 18 months in Chinese people from the Republic of China but higher levels of continuing bonds are related to higher levels of distress among the respondents from the US (Lalande \& Bonanno, 2006). Worthy of note is the study by Lalande and Bonanno is not conclusive. Another American psychologist, Robert Neimeyer and his colleagues found, among American people, that 'bereaved persons who remain closely bonded to their loved ones but who are unable to integrate the loss into a more ample system of personal meaning are at greatest risk for bereavement complications' (Neimeyer, Baldwin, \& Gillies, 2006, p. 733). Thus, it appears that continuing bonds with the deceased would have therapeutic value for bereaved individuals only if they are able to attach meaning to the continuing bonds.

The recent finding by Neimeyer et al. (2006) together with the observation that Chinese tend to perceive a person in relational terms (Koo, Tin, Koo, \& Lee, 2005), may have offered some explanation to the findings reported by Lalande and Bonanno (2006). Given that Chinese are relatively more collectivistic than North Americans, they may find it a lot easier to attach meaning to continuing bonds. With this greater ease in perceiving meaning in continuing bonds, Chinese people would tend to benefit from continuing bonds more than the North Americans, thus supporting Lalande and Bonanno's findings (2006).

The tendency to perceive a person in relational terms may also explain the observation that integration of his late spouse's identity was therapeutic for Max, the Chinese widower featured in this article. Seeing the self in relational terms, Max would probably have difficulty in creating a new identity independent of that of his late spouse's. Taking on an identity devoid of his wife's may have caused him to perceive himself as an incomplete person. It is only through the integration of his late spouse's identity that he was able to come to terms with his need to perceive himself in relational terms.

Practitioners may be well advised to explore whether the organ recipients are able to attach any meaning to continuing bonds with the deceased organ donor. It is only when their clients are able to attach meaning to continuing bonds with the deceased should they attempt to promote continuing bonds to their clients. Given 


\section{I. M. H. Woo and C. L. W. Chan}

the findings from the recent literature, it also appears that continuing bonds may be one valuable resource for practitioners who have encountered immense difficulty helping Chinese bereaved individuals achieve healthy adjustment to conjugal loss. However, given that this report is written based on only one case it is difficult to generalise efficacy of continuing bonds through the integration of the deceased's identity into one's own life in helping Chinese individuals achieve healthy adjustment.

\section{Conclusion}

Though the guilt experienced by an organ recipient over the death of a related organ donor can be intense, it does not mean that the recipient is trapped forever in a state of guilt. Growth is possible for the recipient and continuing bonds with the deceased donor may be a means to help promote growth in the organ recipient overwhelmed with grief. Despite the use of only one informant in this article, it has responded well to Klass' (2006) call for cultural narratives in enhancing our understanding of continuing bonds.

\section{Acknowledgement}

The findings reported in this article were taken from a larger study conducted by the first author in fulfilment of the requirements of the Master of Philosophy programme offered by the Department of Social Work and Social Administration in the University of Hong Kong. The authors would like to acknowledge the assistance provided by Shatin Multi-service Centre for the Elderly, an elderly daycare centre managed by the Evangelical Lutheran Church Social Service of Hong Kong.

\section{REFERENCES}

Blacher, R. S. (2000). "It isn't fair": Postoperative depression and other manifestations of survivor guilt. General Hospital Psychiatry, 22(1), 43-48.

Bowlby, J. (1998). Attachment and loss: Volume 3. Loss: Sadness and depression. London: Pimlico. (Original work published in 1980).

Cantarovich, F. (2002). The organ shortage: A social paradox to be reversed. Transplantation Proceedings, 34, 3031-3034.

Chan, C. L. W., Chow, A. Y. M., Ho, S. M. Y., Tsui, Y. K. Y., Tin, A. F., Koo, B. W. S., ET AL. (2005). The experience of Chinese bereaved persons: A preliminary study of meaning making and continuing bonds. Death Studies, 29(10), 923-947.

Chan, H., \& LEE, R. P. L. (1995). Hong Kong families: At the crossroads of modernism and traditionalism. Fournal of comparative family studies, 26(1), 83-99.

Chui, A. K. K. (2002). Liver transplantation in Hong Kong. Hong Kong Medical fournal, 8(4), 232 233.

DeSPElder, L. A., \& STRICKLAND, A. L. (2005). The last dance: Encountering death and dying (7th ed.). New York: McGraw-Hill.

KhouZAm, H. R., \& KissmeYeR, P. (1997). Antidepressant treatment, posttraumatic stress disorder, survivor guilt ad spiritual awakening. Fournal of Traumatic Stress, 10(4), 691-696.

KLASS, D. (2006). Continuing conversation about continuing bonds. Death Studies, 30(9), 843-858. 
Klass, D. Silverman, P. R. \& Nickman, S. L. (Eds.). (1996). Continuing bonds: New understandings of grief. Philadelphia, PA: Taylor and Francis.

Koo, B. W. S., Tin, A. F., Koo, E. W. K., \& Lee, S. M. (2005). When East meets West: Implications for bereavement counseling. In C. L. W. CHAN \& A. Y. M. CHOw (Eds.), Death, dying and bereavement: A Hong Kong Chinese experience (pp. 261-271). Hong Kong: Hong Kong University Press.

Lalande, K. M., \& Bonanno, G. A. (2006). Culture and continuing bonds: A prospective comparison of bereavement in the United States and the People's Republic of China. Death Studies, 30(4), 303-324.

LAU, S. K. (1981). Chinese familism in an urban-industrial setting: The case of Hong Kong. fournal of Marriage and the Family, 43(4), 977-992.

Miyagi, S., Kawagishi, N., Fujimori, K., Sekigushi, S., Fukumori, T., Akamatsu, Y., et al. (2005). Risks of donation and quality of donors' life after living donor liver transplantation. Transplant International, 18(1), 47-51.

Neimeyer, R. A., Baldwin, S. A., \& Gillies, J. (2006). Continuing bonds and reconstructing meaning: Mitigating complications in bereavement. Death Studies, 30(8), 715-738.

NiederLAND, W. G. (1981). The survivor syndrome: Further observations and dimensions. Fournal of the American Psychoanalytic Association, 29, 413-425.

Port, F. K., Merion, R. M., Finley, M. P., Goodrich, N. P., \& Wolfe, R. A. (2007). Trends in organ donation and transplantation in the United States, 1996-2005. American fournal of Transplantation, 7 (Part 2) (5), 1319-1326.

RANDO, T. A. (1993). Treatment of complicated mourning. Champaign, IL: Research Press.

SANNER, M. A. (2003). Transplant recipients' conceptions of three key phenomena in transplantation: The organ donation, the organ donor, and the organ transplant. Clinical Transplant, 17(4), 391-400.

Shanteau, J., \& Skowronski, J. J. (1990). The decision to donate organs: An informationintegration analysis. In J. SHANTEAU \& R. J. HARRIS (Eds.), Organ donation and transplantation: Psychological and behavioral factors (pp. 59-67). Washington, DC: American Psychological Association.

Silverman, P. R., \& Klass, D. (1996). Introduction: What's the problem? In D. Klass, P. R. Silverman, \& S. L. Nickman (Eds.), Continuing bonds: New understandings of grief (pp. 3-27). Philadelphia, PA: Taylor and Francis.

VASTAG, B. (2003). Living-donor transplants reexamined: Experts cite growing concerns about safety of donors. The fournal of the American Medical Association, 290(2), 181-182. 